\title{
Impact of Petrophysical Properties on Hydraulic Fracturing and Development in Tight Volcanic Gas Reservoirs
}

\author{
Yinghao Shen, ${ }^{1,2}$ Mianmo Meng, ${ }^{1}$ Tao Liu, ${ }^{3}$ Hongkui Ge, ${ }^{1,4}$ and Yuelei Zhang \\ ${ }^{1}$ Unconventional Natural Gas Institute, China University of Petroleum-Beijing, Beijing, China \\ ${ }^{2}$ Texas Tech University, Lubbock, TX, USA \\ ${ }^{3}$ Oil \& Gas Technology Research Institute, Changqing Oilfield Company, Xian, China \\ ${ }^{4}$ China University of Petroleum-Beijing at Karamay, Xinjiang, China \\ ${ }^{5}$ CNODC Brasil Petroleo E Gas Ltda, Rio de Janeiro, RJ, Brazil \\ Correspondence should be addressed to Yinghao Shen; shenyinghao@126.com and Mianmo Meng; mmmcup@163.com
}

Received 29 July 2017; Accepted 12 November 2017; Published 13 December 2017

Academic Editor: Ebrahim Fathi

Copyright (c) 2017 Yinghao Shen et al. This is an open access article distributed under the Creative Commons Attribution License, which permits unrestricted use, distribution, and reproduction in any medium, provided the original work is properly cited.

\begin{abstract}
The volcanic reservoir is an important kind of unconventional reservoir. The aqueous phase trapping (APT) appears because of fracturing fluids filtration. However, APT can be autoremoved for some wells after certain shut-in time. But there is significant distinction for different reservoirs. Experiments were performed to study the petrophysical properties of a volcanic reservoir and the spontaneous imbibition is monitored by nuclear magnetic resonance (NMR) and pulse-decay permeability. Results showed that natural cracks appear in the samples as well as high irreducible water saturation. There is a quick decrease of rock permeability once the rock contacts water. The pores filled during spontaneous imbibition are mainly the nanopores from NMR spectra. Full understanding of the mineralogical effect and sample heterogeneity benefits the selection of segments to fracturing. The fast flowback scheme is applicable in this reservoir to minimize the damage. Because lots of water imbibed into the nanopores, the main flow channels become larger, which are beneficial to the permeability recovery after flow-back of hydraulic fracturing. This is helpful in understanding the APT autoremoval after certain shut-in time. Also, Keeping the appropriate production differential pressure is very important in achieving the long term efficient development of volcanic gas reservoirs.
\end{abstract}

\section{Introduction}

Compared to the development of tight sand reservoirs, there is less research focused on the development of volcanic reservoirs. A volcanic reservoir is a type of low porosity and low permeability reservoir. At the same time, anisotropy is a typical characteristic of volcanic formation due to its complex diagenetic environment [1-3]. Thus, developing this type of reservoir is very challenging. Using a horizontal well with multistage hydraulic fracturing is an important technique for developing volcanic reservoirs. However, for prolific formations, lots of fracturing fluid is retained in the formation after flow-back. Thus, the permeability decreases, and aqueous phase trapping (APT) appears. APT occurs after drilling, hydraulic fracturing, and workover. APT is caused by fluid filtrating into the formation to reduce the formation permeability [4-6]. However, after the well has been shut-in for some time, the permeability of volcanic reservoirs increases and the APT can be autoremoved to some extent, similar to gas shale $[7,8]$. The combination of applying multilateral horizontal drilling and multistage hydraulic fracturing has successfully unlocked unconventionally tight hydrocarbon reservoirs. However, field data show that only a fraction of the large water volume used in hydraulic fracturing treatments is recovered during the flow-back operation. The spontaneous imbibition properties of tight sand and shale reservoirs have been investigated by many experts [9-14]. However, there is less research related to volcanic reservoirs.

Tight gas reservoirs have strong properties of stress sensitivity, which tremendously reduce production in quickreleasing pressure environments. Lowering the pore pressure as gas is produced increases the confining stresses on the reservoir rock, causing it to compact. This compaction causes a reduction in the effective pore diameter, resulting in a 
TABLE 1: Dimensions, porosity, and permeability of various samples.

\begin{tabular}{|c|c|c|c|c|}
\hline Sample & Diameter $(\mathrm{mm})$ & Length (mm) & Porosity (\%) & $\begin{array}{l}\text { Dry samples pulse-decay } \\
\text { permeability }(\mathrm{mD})\end{array}$ \\
\hline $\mathrm{L} 1$ & 24.88 & 11.35 & 7.77 & 0.0078 \\
\hline L2 & 24.96 & 20.46 & 6.85 & 0.0018 \\
\hline L3 & 24.91 & 10.93 & 16.07 & 0.036 \\
\hline $\mathrm{L} 4$ & 24.88 & 10.05 & 16.12 & 0.0078 \\
\hline L5 & 24.84 & 25.69 & 16.41 & 0.010 \\
\hline L6 & 24.84 & 12.49 & 7.07 & 0.00056 \\
\hline L7 & 24.73 & 13.60 & 6.60 & 0.00049 \\
\hline L8 & 24.85 & 19.89 & 4.23 & 0.00083 \\
\hline L9 & 24.86 & 50.61 & 6.88 & 0.00041 \\
\hline L10 & 24.88 & 53.24 & 7.00 & 0.00027 \\
\hline L11 & 24.88 & 51.34 & 2.92 & 0.00019 \\
\hline $\mathrm{L} 12$ & 24.93 & 50.01 & 1.60 & 0.00038 \\
\hline L13 & 24.77 & 50.79 & 4.24 & 0.00013 \\
\hline L14 & 25.35 & 50.69 & 2.01 & 0.0020 \\
\hline L15 & 24.78 & 50.36 & 2.00 & 0.00015 \\
\hline L16 & 24.94 & 50.87 & 1.25 & 0.00067 \\
\hline
\end{tabular}

decreased permeability. This effect has been studied by several authors [15-21]. In recent years, low-field nuclear magnetic resonance (NMR) has become a quick, lossless, and effective means of quantitative microstructural characterization of rock formations, and it has been widely used in fine reservoir descriptions of clastic rocks, carbonate, coal, and other conventional reservoirs in the laboratory and well logging. Thus, the nuclear magnetic resonance technique has become a useful tool to research varieties of rock types [22-27]. To obtain a high production of volcanic reservoirs, additional research on these formations should be carried out. This paper focuses on investigating some petrophysical properties of volcanic rocks in Songliao Basin, China, to provide some reservoir information for the efficient development.

The study area is located in Yingtai of Jilin, China. The volcanic rock in this region is extremely heterogeneous with low porosity and low permeability. The multistage horizontal well with hydraulic fracturing procedure is a necessary technique to develop the resources in this location.

This paper contributes to the understanding of APT autoremoval of the prolific volcanic reservoirs and is beneficial for determining the optimal production differential pressure for efficiently developing this type of reservoir.

\section{Samples}

The physical parameters of some samples are listed in Table 1. Volcanic rock samples are mainly taken from the Lower Cretaceous Yingcheng Formation in Yingtai of Jilin, China. The samples were dried at $65^{\circ} \mathrm{C}$ before the experiment, until the mass became constant. Sample porosities were measured with a helium porosimeter (KXD-III type). The sample pulse-decay permeability was determined by an ultra-low permeability measurement instrument (YRD-CP200 type).
Confining pressure was exerted by water, while pore pressure was exerted by helium. The test temperature was $25^{\circ} \mathrm{C}$. The porosity and permeability of the volcanic rocks fluctuated greatly. Some samples have similar porosity, but their permeability differs tremendously. This characteristic may account for the heterogeneity of the volcanic reservoir complex. The samples of L1 and L2 were selected for the spontaneous imbibition test, monitored by nuclear magnetic resonance equipment. The main magnetic field had a frequency of $23 \mathrm{MHz}$, the signal superposition time was 64, the waiting time was $3000 \mathrm{~ms}$, and the echo spacing was $0.116 \mathrm{~ms}$. Samples L3-L8 were selected for one surface spontaneous imbibition test, monitored by a pulse-decay permeability apparatus under a confining pressure of $8 \mathrm{MPa}$ and pore pressure of $5 \mathrm{MPa}$. Samples L9-L16 were selected for a stress sensitivity experiment under a confining pressure of $10-30 \mathrm{MPa}$ and pore pressure of $6 \mathrm{MPa}$. All these experiments occurred at atmospheric conditions except for the special illustration.

\section{Experimental Methods}

Bulk mineralogical compositions were derived from XRD (X-ray diffraction) patterns, which were measured by a D/max 2500 diffractometer. This experiment was carried out at the State Key Laboratory of Petroleum Resources and Prospecting, in China University of Petroleum, Beijing.

Standard thin section preparation and analysis were carried out here to investigate the regular micropore structure and mineral distribution. In this experiment, the blue epoxy was injected into the rock pores under vacuum. Thin sections were obtained by polishing the bulk rock after the liquid glue was solidified. Due to the pores in the rock being occupied by color glue, the pores and cracks could be distinguished clearly by a microscope. This experiment was also carried out at the State Key Laboratory of Petroleum Resources and 
Prospecting in China University of Petroleum, Beijing, using a LEICA DFC550 made in Germany.

Centrifuge analyses were conducted by a centrifuge machine with an arm radius of $17 \mathrm{~cm}$. The samples were dried until the mass became constant. Subsequently, the samples were saturated with liquid after they were vacuumed and centrifuged again. The liquids used here were distilled water and anion water and the anion water consisted of sodium dodecyl sulfate (SDS) and distilled water. This experiment was performed at the Education Ministry Key Laboratory of Petroleum Engineering in China University of Petroleum, Beijing.

A nuclear magnetic resonance (NMR) experiment was performed while spontaneous imbibition was carried out using the MicroMR23-025V equipment in Shanghai Niumag Corporation. The principle of NMR is based on the difference in the transverse relaxation times of liquids with different pore sizes-the larger the pores, the longer the transverse relaxation time. The main magnetic field had a frequency of $23 \mathrm{MHZ}$, the signal superposition time was $64 \mathrm{~ms}$, the wait time was $3000 \mathrm{~ms}$, and the echo spacing was $0.116 \mathrm{~ms}$. The steps of testing are listed as follows. (1) The dry sample was measured by NMR and analytic balance. (2) The sample was soaked into the liquid for a period of time, $150 \mathrm{~min}$ for $\mathrm{L} 1$ and $120 \mathrm{~min}$ for L2, respectively. Then, it was taken out and dried with adsorbent paper, and the oncoming test time interval is about $30 \mathrm{~min}$ for both of them. (3) The wet sample was measured by NMR and analytic balance. (4) Steps (2) and (3) were repeated. After the experiment, the spectra as well as the liquid content as a function of imbibition time were obtained.

A pulse-decay permeability experiment in the process of spontaneous imbibition was conducted by the pulsedecay permeability measurement instrument (YRD-CP200 type) at the State Key Laboratory of Petroleum Resources and Prospecting in China University of Petroleum, Beijing. The measurement principle is based on the pressure-decay between the two ends of samples. The logarithm of deferential pressure is a linear function of time. Sample permeability is closely related to the linear slope. The main equations are listed as follows, which is consistent with Cui et al. 2009 [28].

Dimensionless differential pressure $\Delta p_{D}$,

$$
\Delta p_{D}=\frac{p_{u}(t)-p_{d}(t)}{p_{u}(0)-p_{d}(0)} .
$$
30],

At large experimental time, the $\Delta p_{D}$ can be simplified [29,

$$
\operatorname{In}\left(\Delta p_{D}\right)=\operatorname{In}\left(f_{0}\right)+s_{1} t
$$

$f_{0}$ is constant and $s_{1}$ is shown as

$$
s_{1}=\frac{k f_{1} A\left(1 / V_{u}-1 / V_{d}\right)}{\mu L c_{g}},
$$

where $f_{1}$ is

$$
f_{1}=\frac{\theta_{1}^{2}}{a}+b
$$

where $a$ and $b$ are

$$
\begin{aligned}
& a=\frac{V_{p}\left(1+f_{a}\right)}{V_{u}} \\
& b=\frac{V_{p}\left(1+f_{a}\right)}{V_{d}} .
\end{aligned}
$$

$\theta_{1}$ is the first root of the following equation:

$$
\tan \theta=\frac{(a+b) \theta}{\theta^{2}-a b} .
$$

At last, the permeability can be expressed as

$$
k=\frac{-s_{1} \mu L c_{g}}{f_{1} A\left(1 / V_{u}+1 / V_{d}\right)} .
$$

In this experiment, only one surface of the sample contacted the liquid to monitor the fracturing fluid filtrating into the formation through the surface of the hydraulic fractures. Our spontaneous imbibition testing was consistent with Ghanbari and Dehghanpour [31]. The detailed steps are listed as follows: (1) the permeability and weight of the sample were measured in dry state; (2) one surface of the sample contacted the liquid for a period of time, which is about 30 50 min in the work, and then it was taken out and dried with adsorbent paper; (3) the permeability and weight of the wet sample were measured; (4) steps (2) and (3) were repeated. After this experiment, the permeability change with imbibition time as well the liquid content as a function of imbibition time can be obtained.

A stress sensitivity experiment was performed by a pulsedecay permeability measurement instrument (YRD-CP200 type) at the State Key Laboratory of Petroleum Resources and Prospecting in China University of Petroleum, Beijing. In this experiment, the permeability was measured under different net confining pressure. In the experimental process, the sample was placed in the pulse-decay permeability equipment, until the entire stress sensitivity experiment was finished.

\section{Results}

4.1. Analysis of Mineral Components of Rock. Tight reservoirs usually have strong heterogeneity in mineral composition. The mineral composition may vary significantly through the rock column in the same formation [32-34].

The mineral contents of various volcanic rocks are listed in Table 2. The samples used for XRD tests were derived from fragments when cutting the standard samples. The quartz and total clays make up most of the content, but plagioclase and $\mathrm{K}$-feldspars are also important constituents. The abundance of calcite, dolomite, and pyrite is nearly zero. Quartz is a mineral important in improving the efficiency of hydraulic fracturing [35]. Clays have a large effect on the adsorption of fracturing fluid in volcanic reservoirs [36].

The important mineralogy of volcanic rock with depth is presented in Figure 1. The samples were named according to their depth-the larger the sample number, the deeper the sample. The depth range is $3806.9 \mathrm{~m} \sim 4101.2 \mathrm{~m}$ and sample 
TABLE 2: Results of XRD mineralogy analyses.

\begin{tabular}{|c|c|c|c|c|c|c|c|c|c|c|c|c|c|c|c|c|}
\hline Samples & L1 & L2 & L3 & L4 & L5 & L6 & L7 & L8 & L9 & L10 & L11 & L12 & L13 & L14 & L15 & L16 \\
\hline Length & 11.35 & 20.46 & 10.93 & 10.05 & 25.69 & 12.49 & 13.60 & 19.89 & 50.61 & 53.24 & 51.34 & 50.01 & 50.79 & 50.69 & 50.36 & 50.87 \\
\hline Type of analysis & & & & & \multicolumn{12}{|c|}{ Bulk \& clay } \\
\hline Weight\% & 100 & 100 & 100 & 100 & 100 & 100 & 100 & 100 & 100 & 100 & 100 & 100 & 100 & 100 & 100 & 100 \\
\hline Quartz & 45.2 & 44 & 55.8 & 44.3 & 41.1 & 53.7 & 13.2 & 43.5 & 44.2 & 36.1 & 51.3 & 33.5 & 45.1 & 39.8 & 42.5 & 36.8 \\
\hline Potassium feldspar & 4.9 & 4.7 & 3.9 & 1.9 & 6.4 & 2.3 & 1.9 & 3.1 & 1.2 & 1.3 & 3.4 & 1.4 & 2.8 & 3.3 & 1.8 & 16 \\
\hline Plagioclase feldspar & 15.6 & 18.9 & 22.4 & 16.2 & 9.5 & 32.7 & 10 & 7.1 & 16 & 9 & 12.3 & 7.7 & 16.9 & 12.7 & 16.8 & 20.0 \\
\hline Calcite & 0 & 0 & 3.7 & 0 & 0 & 1.4 & 0 & 0 & 0 & 0 & 0 & 0 & 0 & 0 & 0 & 1.6 \\
\hline Pyrite & 0 & 1.2 & 0 & 0 & 0 & 0 & 0 & 0 & 0 & 0 & 0 & 0 & 0 & 0 & 0 & 0 \\
\hline Total clay & 34.3 & 31.2 & 14.2 & 37.6 & 43 & 9.9 & 74.9 & 46.3 & 38.6 & 53.6 & 33 & 57.4 & 35.2 & 44.2 & 38.9 & 40.0 \\
\hline
\end{tabular}

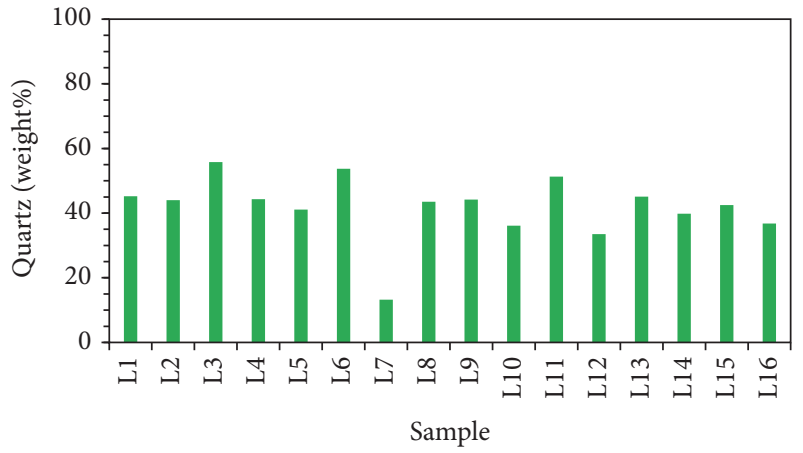

(a)

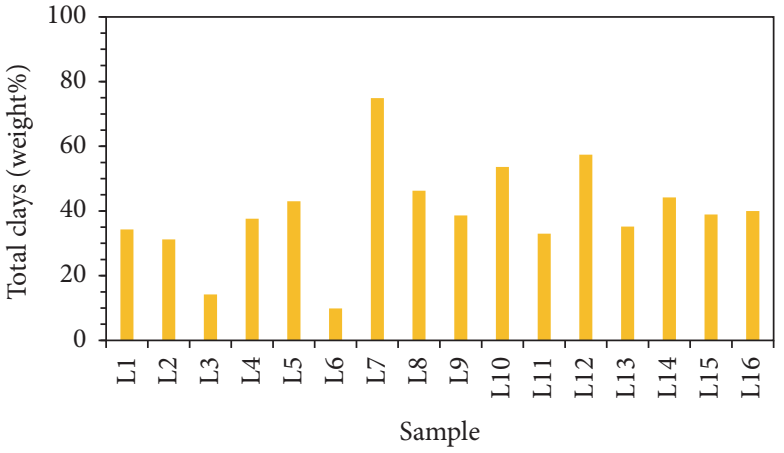

(b)

FIGURE 1: (a) Quartz on the left, (b) total clays on the right of various volcanic samples from various depths.

interval between two samples is about $12.5 \mathrm{~m}$. As shown in Figure 1, the quartz content and clay content do not have clear tendency with depth. The minerals are usually used as an evaluation criterion for selecting the best segment for hydraulic fracturing. More brittle minerals, such as quartz, and less clays are usually better for hydraulic fracturing in unconventional reservoir [37], which is widely accepted as one important criterion. However, the trends with depth are not clear enough in the research area, which means that the segment choice of hydraulic fracturing needs more consideration by the mineral components evaluation. It is critical to get the whole formation mineral type and content to get the more favorable formation segment for developing fractures.

4.2. Casting Thin Sections. Three photomicrographs from thin section analysis of volcanic rock casts are shown in Figure 2. There are microfractures at different scales; the width of microfractures is $0.02 \sim 0.2 \mathrm{~mm}$. The manufacturing operation of the thin sections follows the basic direction in the lab. The microfractures shown in Figure 2 are more likely the original microfractures of samples.

The potential influence of microfractures should be considered during hydraulic fracturing and gas production. Firstly, microfractures contribute to sample permeability stress sensitivity. The permeability is difficult to recover after confining pressure unloading while there are more microfractures. Thus, it needs further study on permeability with effective pressure, which will be conducted later. Secondly, microfractures are beneficial to generation of hydraulic fracture network. At the same time, microfractures are important flow channels for gas production. If fractures connect to each other under the hydraulic pressure, formation permeability can be improved greatly.

4.3. Centrifuge Testing. Results of centrifuge testing on volcanic rock are presented in Figure 3. Samples with distilled water have a higher irreducible water saturation than samples with anion water, except for sample $C$. The average irreducible water saturation of samples with distilled water is $75.5 \%$, while the average irreducible water saturation of samples with anion water is $62.6 \%$. Experimentally, the reservoir damage caused by fracturing liquid filtration can be reduced by using the anion-water-based fluid.

4.4. Monitor Spontaneous Imbibition Using Nuclear Magnetic Resonance Technique. Nuclear magnetic resonance technique was used in the experiments to clearly distinguish the distribution of the imbibed liquid with the soaking time in volcanic rocks. X-ray CT imaging technique has been previously used to research the spontaneous imbibition of low permeability sandstones [38]. However, this method cannot distinguish the exact distribution of the imbibed liquid, that is, the liquid distribution in the different pore sizes. The NMR technique has been widely used in rock analysis [39, 40]. The NMR method involves the motion of protons (Hydrogen 


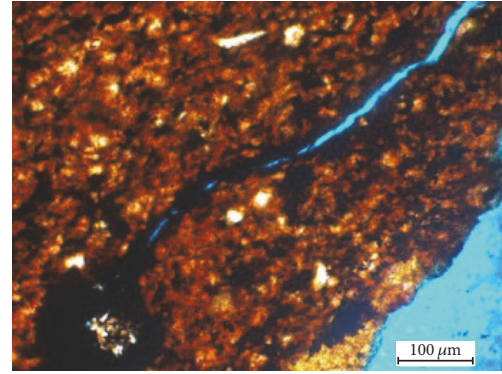

(a1)

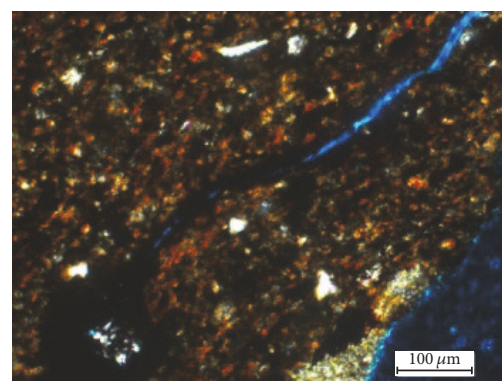

(a2)

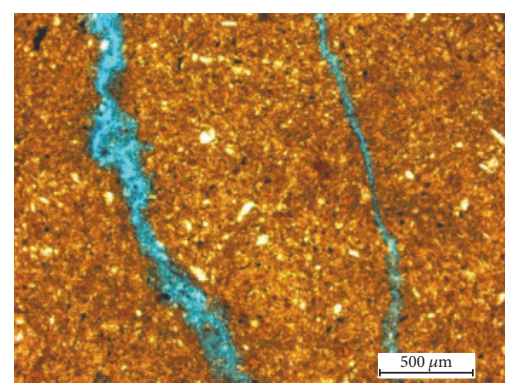

(b1)

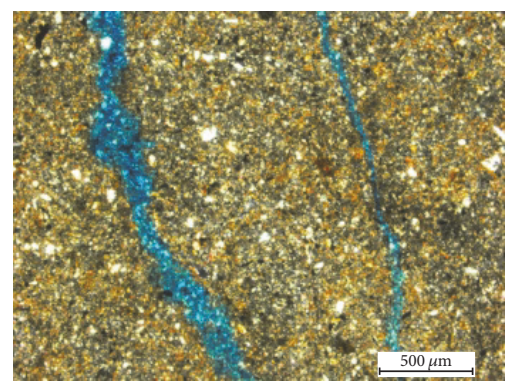

(b2)

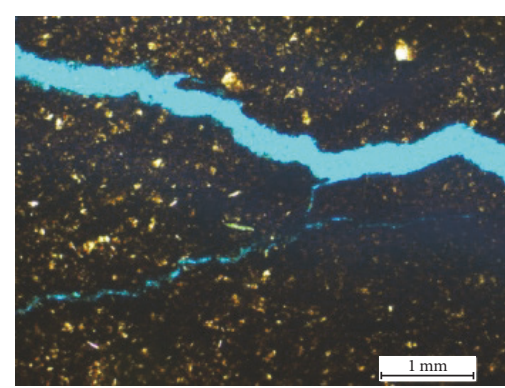

(c1)

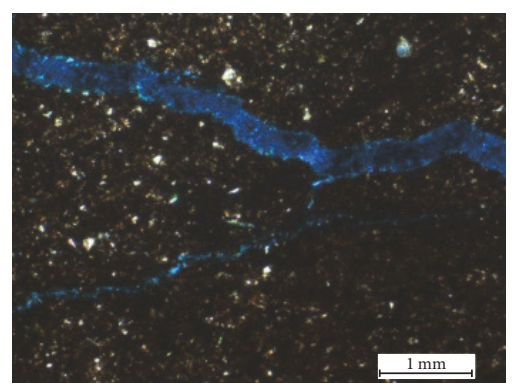

(c2)

FIGURE 2: Casting film of three volcanic rock samples under plane polarized light (a1, b1, and c1) and perpendicular polarized light (a2, b2, and c2).

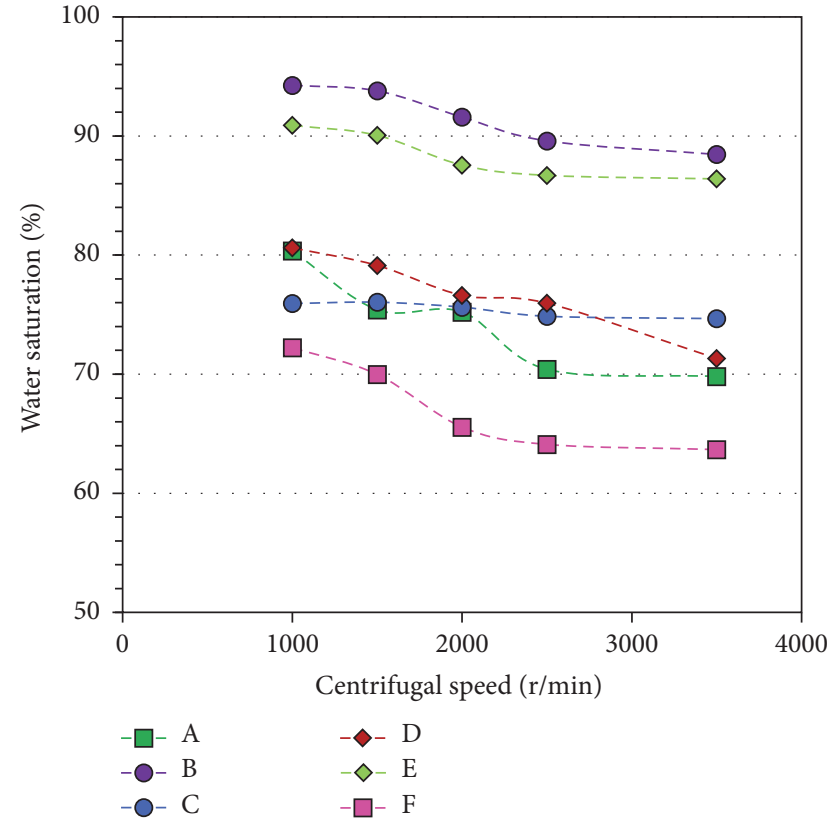

(a)

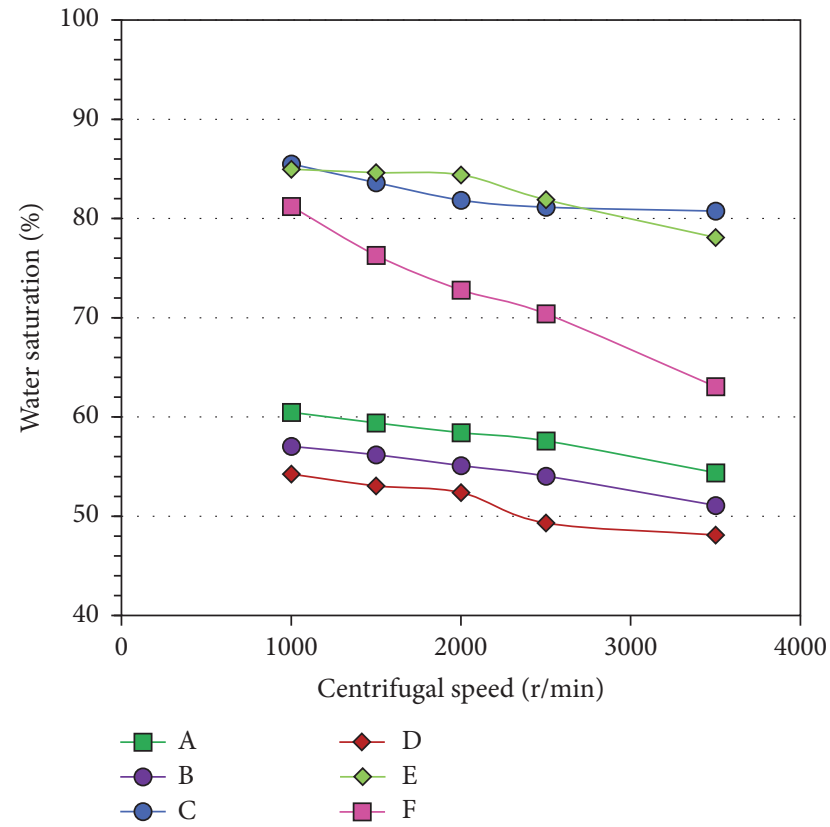

(b)

Figure 3: Centrifuge experiments for various volcanic samples: (a) distilled water and (b) anion water.

${ }^{1} \mathrm{H}$ ) occurring in water and hydrocarbon fluids relative to the porous rock [41]. The fluid in large pores has a longer T2 value because more nuclei are available to exhibit the NMR effect, and the fluid in small pores has a short T2 value. The T2 relaxation time is inversely proportional to the specific surface of samples [42]. The T2 spectra as a function of spontaneous imbibition time is shown in Figure 4.
The sample L1 has three isolated peaks (left peak area $\gg$ middle peak area $\gg$ right peak area). Its T2 spectrum fluctuates to a certain degree according to the peak area change, where the area at $184 \mathrm{~min}$ is a little larger than that at $208 \mathrm{~min}$. However, it is understandable because of the experiment error. The T2 spectrum area becomes stable in less than $151 \mathrm{~min}$. Its right peak area is very small, which 


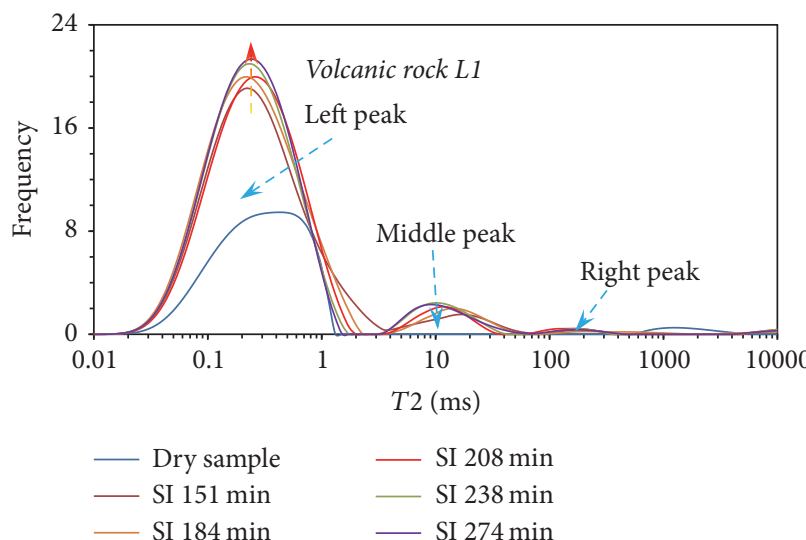

(a)

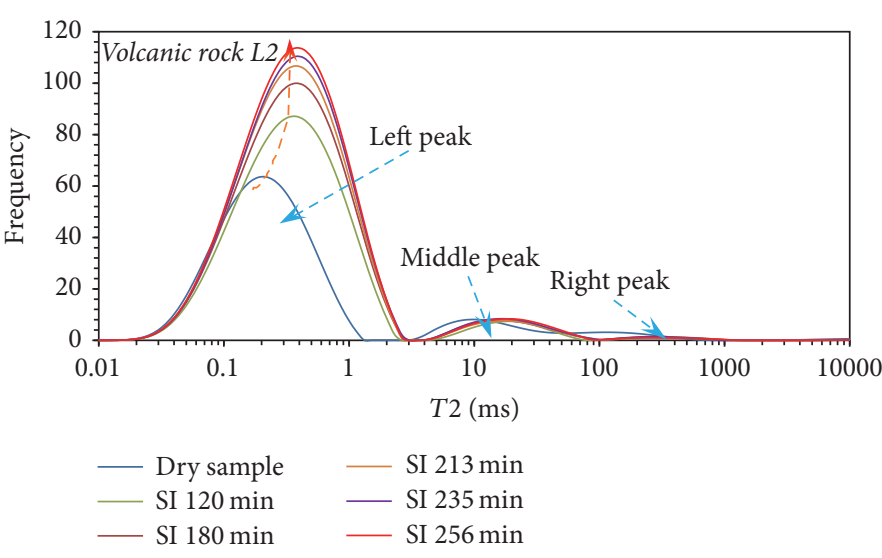

(b)

FIgURE 4: The T2 spectra of samples: L1 and L2 for various spontaneous imbibition times (SI is the acronym spontaneous imbibition).

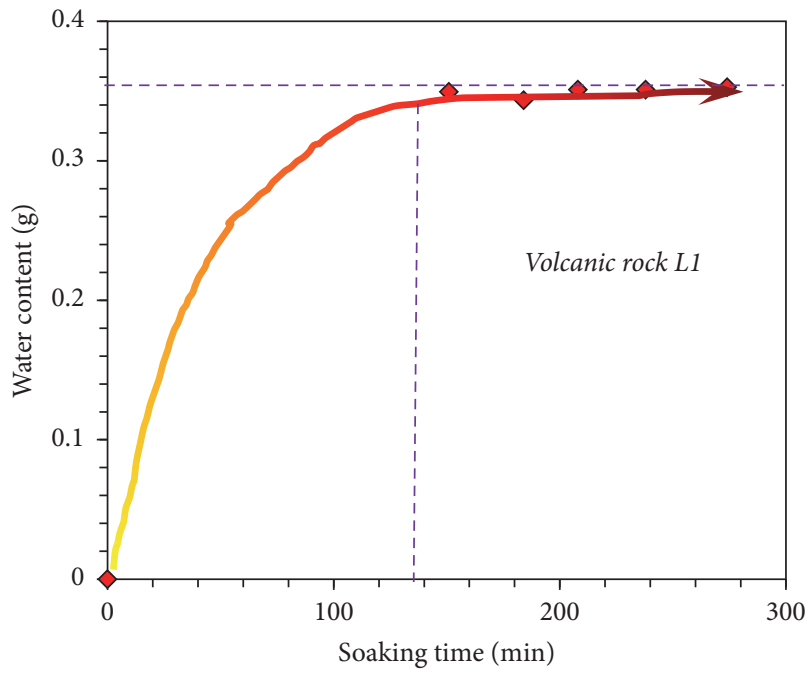

Water content

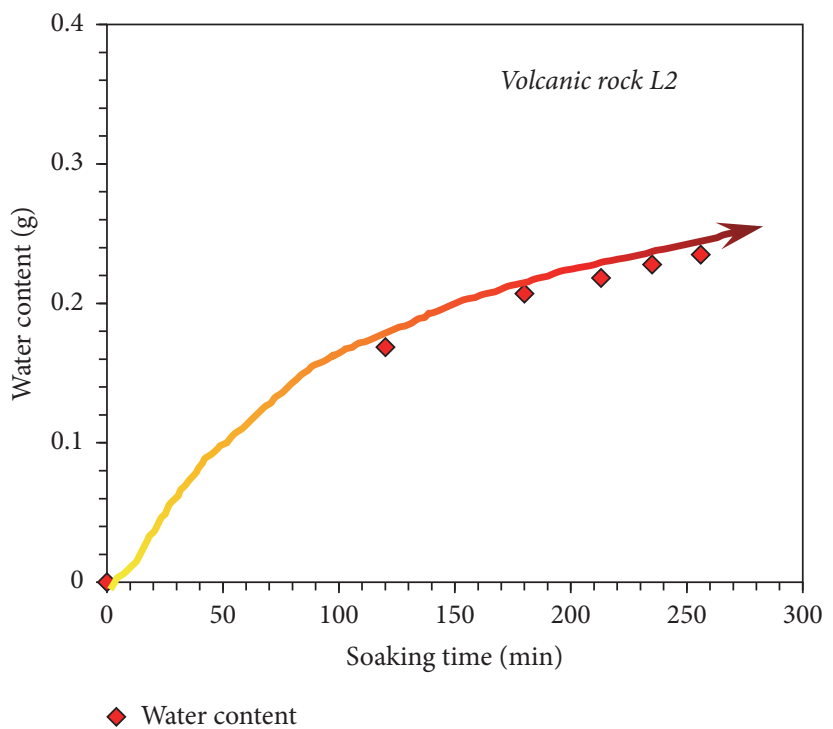

FIGURE 5: The water content as a function of soaking time: volcanic rocks L1 and L2. During imbibition the samples were soaked into the distilled liquid entirely. The trend curve represents the direction of water content change.

indicates that the number of large pores and fractures is small. The left peak area takes up the largest proportion, which shows that the micropores dominate the porosity of the main sample.

The sample L2 has three isolated peaks (left peak area $\gg$ middle peak area $\gg$ right peak area). Its right peak area is too small to be detected clearly. Its middle peak and right peak area become stable very quickly, but its left peak area increases gradually after the sample is soaked in water for $256 \mathrm{~min}$, which indicates that its micropores have a slow imbibition rate. If the rate of fracturing fluid flow-back is fast, the reservoir will have less damage in this type of volcanic formation.

Figure 5 shows the water content of samples L1 and L2 as a function of spontaneous imbibition time. The sample weight is determined by analytic balance. As the sample is soaked in water, the water content of volcanic rock L1 becomes stable by $120 \mathrm{~min}$. However, the water content of volcanic rock L2 is still increasing by the same elapsed time. This phenomenon indicates that volcanic rocks have strong heterogeneity.

4.5. Monitor Spontaneous Imbibition Using Pulse-Decay Permeability Technique. The experiments concerning spontaneous imbibition have been performed with many types of rocks, especially sandstones and shales [43-47]. These studies have paid much attention to the damage caused by fracturing fluid filtration under the effect of spontaneous imbibition. At the same time, many types of additives have been added to the fracturing fluid to reduce the filtration rate and protect the target formation. Through reducing the fracturing fluid filtration, the formation permeability can be maintained. However, less research has focused on volcanic rocks. In this section, we used the pulse-decay permeability technique to monitor the rock permeability change with imbibition time. 
TABLE 3: The permeability loss after rock imbibition.

\begin{tabular}{lccc}
\hline Samples & Initial permeability $[\mathrm{mD}]$ & Final permeability [mD] & Permeability loss [\%] \\
\hline L3 & 0.0355 & 0.00418 & 88.2 \\
L4 & 0.00773 & 0.000175 & 97.7 \\
L5 & 0.01 & 0.00027 & 97.3 \\
L6 & 0.000556 & 0.0000888 & 84.0 \\
L7 & 0.000486 & 0.0000674 & 86.1 \\
L8 & 0.000828 & 0.000306 & 63.0 \\
\hline
\end{tabular}

The rocks contacted the liquid at only one surface to simulate the fracturing fluid filtrating into the formation from the fracture surface.

The volcanic rock permeability as well as the water content is shown in Figure 6 as a function of spontaneous imbibition time. The test condition is as follows: one surface of the sample contacts the distilled water to simulate the fracturing fluid filtrating into the formation through the fracture surface. The figure indicates that the permeability decreases quickly in the early period. The permeability of sample L3 reaches stability after the sample has been soaked for $100 \mathrm{~min}$. At the same time, its water content approaches stability. However, the other five samples have different characteristics. Their water content continues to increase significantly while their permeability becomes stable. Thus, the water imbibed into the volcanic rock in the late period has little influence on the sample permeability based on L4 to L8; here the permeability change is the phenomenon of macro, where it is hard to distinguish the clay effect. However, in the micro scope the water is continually imbibed into micropores, which may be controlled by clay minerals and nanopores in the matrix. The fluids enters into the micropores by clay adsorption and capillary pressure. So the phenomenon that permeability does not change too much in the later period may occur because the fluid enters into the micropores, which have less contribution to the rock permeability than the main flowing channel.

The permeability change may have important influences to the flow-back scheme selection. The normal flow-back scheme includes fast flow-back, normal flow-back, and soaking back after fracturing. The basic consideration of the flowback scheme is the balance between fracture propping and water invasion. The fast flow-back can be used to minimize the water invasion and permeability loss. According to Figure 6 , the permeability of the six samples decreases significantly, which is about $80 \% \sim 90 \%$ of original permeability and reaches stability very quickly, where the stable times range from $20 \mathrm{~min}$ to $150 \mathrm{~min}$. Therefore, the quick flow-back of fracturing fluid is a better choice to improve the effect of hydraulic fracturing which is beneficial for minimizing the permeability loss by water invasion. The less the fracturing fluid retained in the reservoir, the higher the permeability that can be obtained.

APT autoremoval is based on the liquid migration among different pores after flow-back. In Figure 6, in the late imbibition period, it can be found that permeability keeps constant when imbibition mass still increases. It means that imbibition liquid at later period has no influence on rock permeability. In reservoir condition, after flow-back, liquid can move in some pores which have no contribution to reservoir permeability. Therefore, the gas flowing channels increase. Leak-off can also damage the reservoir permeability. However, after flow-back, when these leak-off liquids filtrate into some pores, which have no influence on reservoir permeability, the damage will decrease.

In addition, we illustrated the permeability loss after rock imbibition which is shown in Table 3 . The permeability loss is calculated as follows: (initial permeability - final permeability)/initial permeability, where the initial permeability refers to the dry sample permeability and the final permeability refers to the final time permeability during imbibition. From the table, we find that the permeability loss is very significant after imbibition. The permeability loss can be as high as 97.7\% during the spontaneous imbibition process. Therefore, abundant fracturing liquid continuously imbibed into the formation damages the formation permeability. Because the water imbibed into formation increases with time, there will be more serious permeability loss; as is shown in Table 3 the permeability loss is in the range of $63 \%$ 97\%. Combining the analysis, we concluded that a fast flow-back scheme after hydraulic fracturing is necessary, because the fast flow-back technique can decrease the interaction time between water and formation, and hence the water imbibed into formation.

4.6. Permeability Stress Sensitivity. The pulse-decay permeability measurement method has been widely recognized as a way to identify the ultra-low permeability rocks $[28,30,48-$ 53]. Because the conventional permeability measurement is based on recording the flow rate during the experiment, the flow rate through the ultra-low permeability rock is too small to be measured exactly under the precision of present equipment. The pulse-decay permeability measurement is based on the change in differential pressure with testing time. It can satisfy the requirements of the ultra-low permeability measurement well. Permeability stress sensitivity has been performed on various rocks, especially the sandstones and shales [54-56]. Pressure drawdown can produce stress sensitivity [57]. Sandstone has less stress sensitivity than shale, which will vary by two to three orders of magnitude when the confining pressure is changed from $3 \mathrm{MPa}$ to $120 \mathrm{MPa}$ and then returned to $3 \mathrm{MPa}$ [58]. In this section, we studied the permeability stress sensitivity of volcanic rocks in detail and propose two formulas.

Results of the sample stress sensitivity are presented in Figure 7. The negative natural logarithmic permeability as a function of net confining pressure is shown in the $y$-axis. 

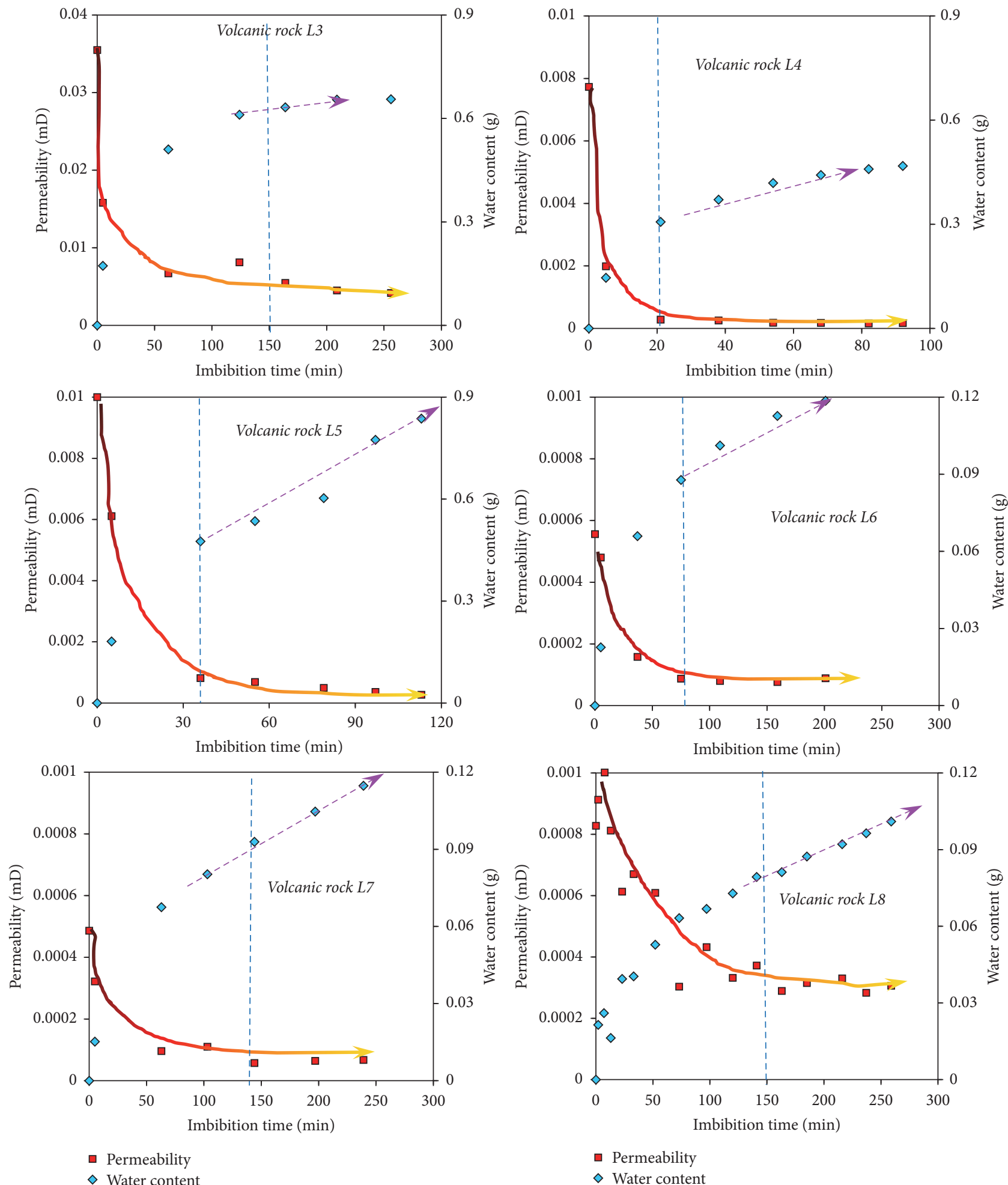

FIGURE 6: Permeability and water content as a function of imbibition time: volcanic rocks L3-L8. The rocks imbibition occurred with only one surface contacting the distilled liquid. The permeability refers to the pulse-decay permeability. The red trend line represents the direction of the permeability change. 

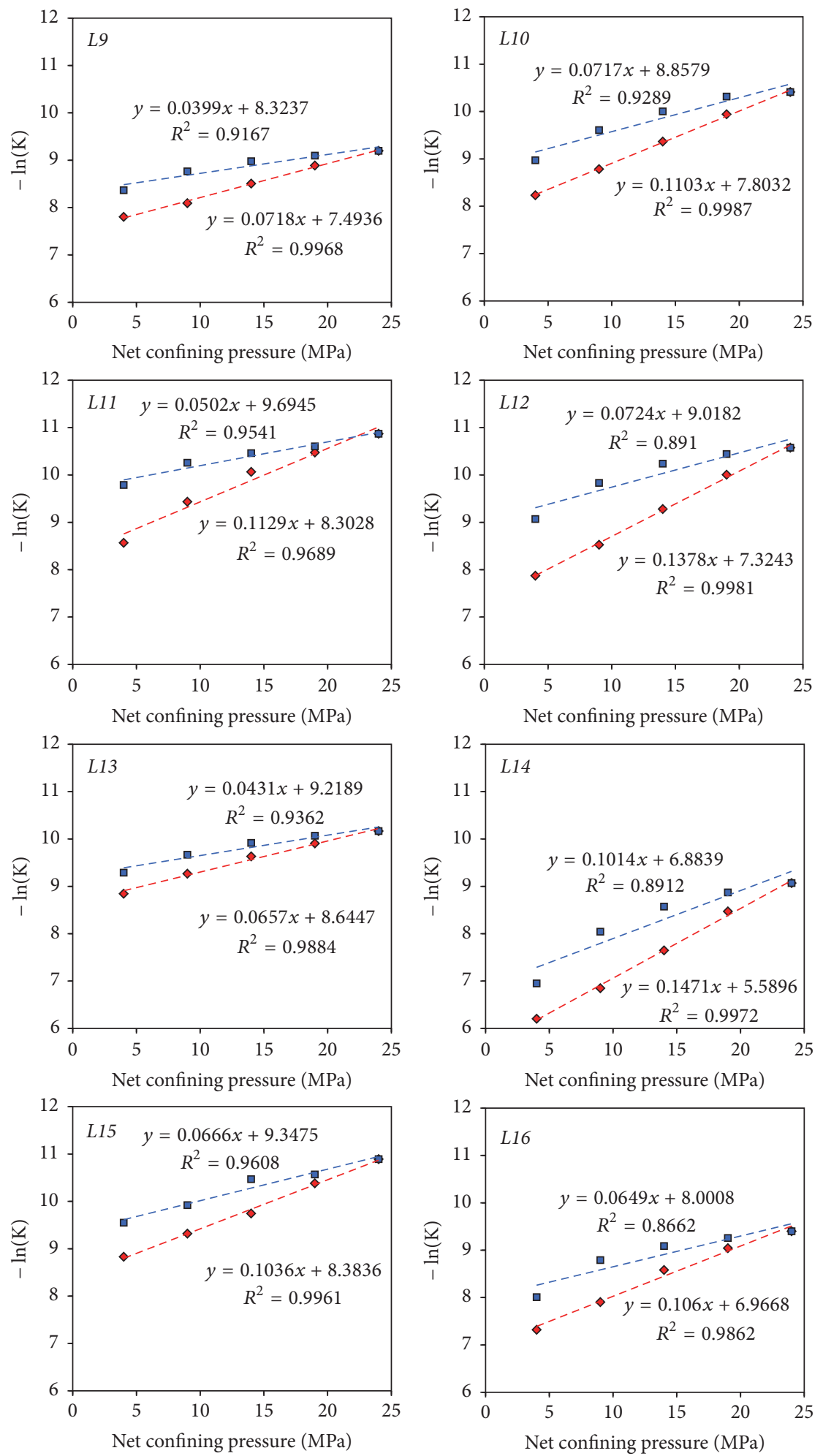

$\diamond$ Loading pressure

$\checkmark$ Loading pressure

- Unloading pressure

- Unloading pressure

FIGURE 7: Negative log pulse-decay permeability as a function of net confining pressure: volcanic rocks L10-L16 for loading pressure and unloading pressure. 
TABLE 4: The permeability change after the samples go through the process of loading pressure and unloading pressure.

\begin{tabular}{lccc}
\hline Samples & $K_{0}(\mathrm{mD})$ & $K_{01}(\mathrm{mD})$ & Loss ratio of permeability $R_{L}(\%)$ \\
\hline L9 & 0.000408 & 0.000232 & 43.14 \\
L10 & 0.000266 & 0.000127 & 52.26 \\
L11 & 0.00019 & 0.000056 & 70.53 \\
L12 & 0.000381 & 0.000115 & 69.82 \\
L13 & 0.000134 & 0.0000924 & 31.04 \\
L14 & 0.00202 & 0.000957 & 52.62 \\
L15 & 0.000146 & 0.0000712 & 51.23 \\
L16 & 0.000662 & 0.000332 & 49.85 \\
\hline
\end{tabular}

Correlation coefficients of $R^{2}=0.9689-0.9987$ are computed for the loading process in each sample. The unloading process has correlation coefficients of $R^{2}=0.8662-0.9608$ generally lower than those observed for the loading process.

A fitted relation is presented for the permeability stress sensitivity of the loading pressure tests:

$$
\begin{aligned}
K & =K_{0} e^{-0.1069 P+0.3964}, \\
R^{2} & =0.8383,
\end{aligned}
$$

where $K$ is the rock pulse-decay permeability at different net confining pressures, $K_{0}$ is the lower net confining pressure permeability, and $P$ is the net confining pressure. We can apply (1) to forecast the permeability of volcanic rock with increasing confining pressure.

Similarly, a fitted relation for the unloading pressure tests can be determined by calculating the volcanic rock permeability:

$$
\begin{aligned}
K & =K_{m} e^{-0.0638 P+1.4056}, \\
R^{2} & =0.7804
\end{aligned}
$$

where $K_{m}$ is the permeability under the maximum confining pressure and the other parameters are the same as in (1). Equation (2) provides us with a power law function to forecast the permeability change by injecting energy to recover the formation fluid pressure.

Here we need to clarify a point that the fitted relation is proposed to understand the permeability stress sensitivity characteristic. The formulas could not be treated as law because there are different relations between different samples. These are more likely fitting relations that help us comprehend the characteristics observed in tested samples.

In Table 4, where $K_{0}$ is the permeability at a net confining pressure of $6 \mathrm{MPa}$ in the loading pressure process and $K_{01}$ is the permeability after the sample completes the process of unloading pressure and the net confining pressure reaches $6 \mathrm{MPa}, R_{L}$ is the loss rate of permeability, which is defined as

$$
R_{L}=\frac{K_{0}-K_{01}}{k_{0}} \times 100 \% .
$$

From the table, the value of $R_{L}$ ranges from $31.04 \%$ to $70.53 \%$. The $R_{L}$ average value is $52.56 \%$. Judging from the average value, the volcanic rock has high permeability stress sensitivity. Usually the production pressure difference is enlarged to get higher production rate when developing the low permeability formation, which means that the bottomhole pressure needs to be much smaller. However, the results here show that a high-pressure difference may result in serious permeability loss, harmful to gas production. So, in the process of developing the volcanic gas reservoir, it is necessary to keep the pore pressure at a high value to reduce the damage caused by the permeability stress sensitivity.

\section{Discussion}

Based on the results of the above experiments, the volcanic rock reservoir in this study has some special characteristics. The quartz content and clay content of the target formation in the Yingtai region do not have clear tendency with depth. So, the segment choice of hydraulic fracturing needs more consideration by the mineral components evaluation. At the same time the average clay content is $39.5 \%$, which is a relatively higher content. There might be formation damage while adopting hydraulic fracturing [59], where the degree is dependent on the clay content and water property injected.

There are some initial microfractures in volcanic reservoirs. When these initial fractures connect with the hydraulic fractures, the reservoir permeability can be improved greatly. However, these microfractures affect the volcanic rock permeability stress sensitivity. Furthermore, the fluid pressure decline has significant influence on the permeability stress sensitivity after hydraulic fracturing is performed. The strong permeability stress sensitivity requires measures for keeping the formation fluid pressure at a high value to realize long term development.

Centrifuge tests indicate that volcanic rocks have high irreducible water saturation. Combined with the field data, the initial water saturation is often far less than the irreducible water saturation, so the reservoirs have a strong capacity to absorb much fracturing liquid. Based on this characteristic, we should take the fracturing fluid imbibition property into consideration when choosing the low filtration fluid to exert hydraulic fracturing.

Volcanic rocks in this work are full of micropores as shown by nuclear magnetic resonance tests. Most micropores have less contribution to the formation permeability, which is presented by way of the pulse-decay permeability measurement in the process of spontaneous imbibition. In the late period of spontaneous imbibition, the sample permeability 
maintains stability while the water content increases. From the nuclear magnetic resonance experiment, we can find that micropores make up most of the porosity. The large pores and quick fractures were filled by liquid. Micropores absorb water slowly. However, these micropores have a strong capacity to absorb a large amount of water, which is beneficial to the permeability recovery and autoremoving aqueous phase trapping after the volcanic reservoir is subjected to hydraulic fracturing.

A large amount of fracturing fluid retention becomes a common phenomenon after hydraulic fracturing is performed in a tight reservoir. However, the permeability can be improved by performing a well shut-in for a period of time. Because micropores have a strong capacity to absorb fracturing liquid from other pores ranging from large pores to micropores, larger pores have a greater contribution to reservoir permeability than micropores, which was demonstrated by the experiments. Under the effect of capillary force, the main gas flowing channel becomes very large, so the entire permeability of the formation increases.

Two equations were proposed to forecast the volcanic reservoir stress sensitivity in the process of loading pressure and unloading pressure. The volcanic rocks have strong permeability stress sensitivity. So, keeping the pore pressure at a high level is very important in efficiently developing volcanic reservoirs.

\section{Conclusions}

The volcanic reservoir is an important tight reservoir. Efficient hydraulic fracturing and development contribute to commercial production of this type of reservoir. The study was trying to get the factors influencing the hydraulic fracturing based on the petrophysical properties. The following conclusions can be made regarding the volcanic reservoir in Songliao Basin, China.

(1) Quartz and clays are the main components in rocks of the research formation. Natural cracks also appear in the samples. These characteristics indicate that, during hydraulic fracturing, abundant quartz and natural cracks promote the generation of network fractures. However, the lack of understanding of the mineralogical effect (i.e., clays) and the challenges on sample heterogeneity increase the difficulty of selection of segments to fracturing.

(2) There is a quick decrease of rock permeability once the rock contacts water, which indicates that aqueous phase trapping (APT) happens when the fracturing fluids are pumped into the formation. The high irreducible water saturation causes the formation to be accompanied by strong spontaneous imbibition due to the low initial water saturation of prolific unconventional reservoirs. Also, the nanopores have strong capillary force, causing the liquid to migrate into the formation, which significantly influences the permeability of the formation. Fast flow-back scheme is applicable in this situation to minimize the damage.

(3) The pores filled during spontaneous imbibition are mainly the nanopores from NMR spectra. Because lots of water imbibed into the nanopores, the main flow channels become larger, which is beneficial to the permeability recovery after flow-back of hydraulic fracturing. This is helpful to understand the APT autoremoval of some volcanic reservoirs.

(4) Strong permeability sensitivity appears in volcanic rocks. Keeping the appropriate production differential pressure is very important in achieving the long term efficient development of volcanic gas reservoirs.

\section{Conflicts of Interest}

The authors declare that there are no conflicts of interest regarding the publication of paper.

\section{Acknowledgments}

This work was supported by the National Natural Science Foundation of China (51604287, 51490652), Science Foundation of China University of Petroleum-Beijing at Karamay (no. RCYJ2016B-01-001), SINOPEC Scientific Research Program "Micro-Nano Capillary Imbibition and Damage Mechanism of Unconventional Oil/Gas Reservoir," and National 973 Project "Control Mechanism for Productive Formations and Repeated Fracturing of Artificial Joint Networks of LowPermeability Reservoirs" (no. 2015CB250903).

\section{References}

[1] N. B. Tchuimegnie Ngongang, P. Kamgang, G. Chazot, A. Agranier, H. Bellon, and P. Nonnotte, "Age, geochemical characteristics and petrogenesis of Cenozoic intraplate alkaline volcanic rocks in the Bafang region, West Cameroon," Journal of African Earth Sciences, vol. 102, pp. 218-232, 2015.

[2] M. Kheirkhah, I. Neill, and M. B. Allen, "Petrogenesis of OIBlike basaltic volcanic rocks in a continental collision zone: Late Cenozoic magmatism of Eastern Iran," Journal of Asian Earth Sciences, vol. 106, pp. 19-33, 2015.

[3] Y. Sun, J. Ying, B. Su, X. Zhou, and J. Shao, "Contribution of crustal materials to the mantle sources of Xiaogulihe ultrapotassic volcanic rocks, Northeast China: New constraints from mineral chemistry and oxygen isotopes of olivine," Chemical Geology, vol. 405, pp. 10-18, 2015.

[4] A. M. Paiaman, J. Moghadasi, and M. Masihi, "Formation damage through aqueous phase trapping in gas reservoirs," in Proceedings of the Deep Gas Conference and Exhibition 2010, DGAS 2010, pp. 43-50, January 2010.

[5] D. B. Bennion, F. B. Thomas, R. F. Bietz, and D. W. Bennion, "Remediation of water and hydrocarbon phase trapping problems in low permeability gas reservoirs," Journal of Canadian Petroleum Technology, vol. 38, no. 8, pp. 39-48, 1999.

[6] L. You and Y. Kang, "Integrated evaluation of water phase trapping damage potential in tight gas reservoirs," in Proceedings of the 8th European Formation Damage Conference, Scheveningen, The Netherlands, 2009.

[7] Y. Shen, H. Ge, C. Li et al., "Water imbibition of shale and its potential influence on shale gas recovery-a comparative study of marine and continental shale formations," Journal of Natural Gas Science and Engineering, vol. 35, pp. 1121-1128, 2016.

[8] Y. Shen, H. Ge, S. Su, D. Liu, Z. Yang, and J. Liu, "Imbibition characteristic of shale gas formation and water-block removal capability," Scientia Sinica Physica, Mechanica \& Astronomica, vol. 47, no. 11, article 114609, 2017. 
[9] S. Akin, J. M. Schembre, S. K. Bhat, and A. R. Kovscek, "Spontaneous imbibition characteristics of diatomite," Journal of Petroleum Science and Engineering, vol. 25, no. 3-4, pp. 149-165, 2000.

[10] M. Chahardowli, A. Zholdybayeva, R. Farajzadeh, and H. Bruining, "Solvent-enhanced spontaneous imbibition in fractured reservoirs," in Proceedings of the EAGE Annual Conference \& Exhibition incorporating SPE Europec., Society of Petroleum Engineers, 2013.

[11] N. R. Morrow and G. Mason, "Recovery of oil by spontaneous imbibition," Current Opinion in Colloid \& Interface Science, vol. 6, no. 4, pp. 321-337, 2001.

[12] Q. Lan, E. Ghanbari, H. Dehghanpour, and R. Hawkes, "Water Loss Versus Soaking Time: Spontaneous Imbibition in Tight Rocks," Energy Technology, vol. 2, no. 12, pp. 1033-1039, 2014.

[13] J. Cai, L. Luo, R. Ye, X. Zeng, and X. Hu, "Recent advances on fractal modeling of permeability for fibrous porous media," Fractals, vol. 23, no. 1, Article ID 1540006, 2015.

[14] J. Cai, X. Hu, B. Xiao, Y. Zhou, and W. Wei, "Recent developments on fractal-based approaches to nanofluids and nanoparticle aggregation," International Journal of Heat and Mass Transfer, vol. 105, pp. 623-637, 2017.

[15] D. Lin, J. Wang, B. Yuan, and Y. Shen, "Review on gas flow and recovery in unconventional porous rocks," Advances in GeoEnergy Research, vol. 1, no. 1, pp. 39-53, 2017.

[16] X. Dou, X. Liao, X. Zhao, H. Wang, and S. Lv, "Quantification of permeability stress-sensitivity in tight gas reservoir based on straight-line analysis," Journal of Natural Gas Science and Engineering, vol. 22, pp. 598-608, 2015.

[17] J. Yang, R. Liu, and H. Liu, "A universal model of stress sensitive coefficient in low permeability reservoir," in Proceedings of the 2011 SREE Conference on Engineering Modelling and Simulation, CEMS 2011, pp. 177-183, August 2011.

[18] Y. Tian, "Experimental study on stress sensitivity of naturally fractured reservoirs," in Proceedings of the SPE Annual Technical Conference and Exhibition, Amsterdam, The Netherlands, 2014.

[19] I. Fatt and D. Davis, "Reduction in Permeability With Overburden Pressure," Journal of Petroleum Technology, vol. 4, no. 12, pp. 16-16, 2013.

[20] A. McLatchie, R. Hemstock, and J. Young, "The Effective Compressibility of Reservoir Rock and Its Effects on Permeability," Journal of Petroleum Technology, vol. 10, no. 06, pp. 49-51, 2013.

[21] D. H. Gray and I. Fatt, "The Effect of Stress on Permeability of Sandstone Cores," SPE Journal, vol. 3, no. 02, pp. 95-100, 2013.

[22] H. Xu, D. Tang, J. Zhao, and S. Li, "A precise measurement method for shale porosity with low-field nuclear magnetic resonance: A case study of the Carboniferous-Permian strata in the Linxing area, eastern Ordos Basin, China," Fuel, vol. 143, pp. 47-54, 2015.

[23] K. E. Washburn and J. E. Birdwell, "Application of binomialedited CPMG to shale characterization," Journal of Magnetic Resonance, vol. 246, pp. 72-78, 2014.

[24] J. Mitchell, T. C. Chandrasekera, D. J. Holland, L. F. Gladden, and E. J. Fordham, "Magnetic resonance imaging in laboratory petrophysical core analysis," Physics Reports, vol. 526, no. 3, pp. 165-225, 2013.

[25] R. Lewis, P. Singer, T. Jiang, E. Rylander, S. Sinclair, and R. H. Mclin, "NMR T2 distributions in the eagle ford shale: reflections on pore size," in Proceedings of the SPE Unconventional Resources Conference, Society of Petroleum Engineers, 2013.
[26] K. Munn and D. M. Smith, "A NMR technique for the analysis of pore structure: Numerical inversion of relaxation measurements," Journal of Colloid and Interface Science, vol. 119, no. 1, pp. 117-126, 1987.

[27] W. E. Kenyon, "Nuclear magnetic resonance as a petrophysical measurement. The International journal of radiation applications and instrumentation," Part E. Nuclear Geophysics, vol. 6, no. 2, pp. 153-171, 1992.

[28] X. Cui, A. M. M. Bustin, and R. M. Bustin, "Measurements of gas permeability and diffusivity of tight reservoir rocks: Different approaches and their applications," Geofluids, vol. 9, no. 3, pp. 208-223, 2009.

[29] A. I. Dicker and R. M. Smits, "Practical approach for determining permeability from laboratory pressure-pulse decay measurements," in Proceedings of the International Meeting on Petroleum Engineering, Society of Petroleum Engineers, November 1988.

[30] S. C. Jones, "A technique for faster pulse-decay permeability measurements in tight rocks," SPE Formation Evaluation, vol. 12, no. 1, pp. 19-24, 1997.

[31] E. Ghanbari and H. Dehghanpour, "Impact of rock fabric on water imbibition and salt diffusion in gas shales," International Journal of Coal Geology, vol. 138, pp. 55-67, 2015.

[32] S. Kale, C. Rai, and C. Sondergeld, "Rock typing in gas shales," in Proceedings of the SPE Annual Technical Conference and Exhibition, Society of Petroleum Engineers.

[33] Z.-Q. Feng, "Volcanic rocks as prolific gas reservoir: A case study from the Qingshen gas field in the Songliao Basin, NE China," Marine and Petroleum Geology, vol. 25, no. 4-5, pp. 416432, 2008.

[34] T. Kawamoto and K. Sato, "Geological modelling of a heterogeneous volcanic reservoir by the petrological method," in Proceedings of the SPE Asia Pacific Conference on Integrated Modelling for Asset Management "Rising to the Challenges of Enhancing our Assets", pp. 97-104, Society of Petroleum Engineers, April 2000.

[35] D. Weng, Q. Lei, Y. Ding et al., "Case Study: Massive hydraulic fracturing in volcanic gas, China," in Proceedings of the SPE Production and Operations Symposium, Society of Petroleum Engineers.

[36] C. M. Fuller and J. M. Sharp Jr., "Permeability and fracture patterns in extrusive volcanic rocks: implications from the welded Santana Tuff, Trans-Pecos Texas," Geological Society of America Bulletin, vol. 104, no. 11, pp. 1485-1496, 1992.

[37] C. H. Sondergeld, K. E. Newsham, J. T. Comisky, M. C. Rice, and C. S. Rai, "Petrophysical considerations in evaluating and producing shale gas resources," in Proceedings of the SPE Unconventional Gas Conference 2010, pp. 99-132, Society of Petroleum Engineers, February 2010.

[38] R. Dutta, C.-H. Lee, S. Odumabo et al., "Experimental investigation of fracturing-fluid migration caused by spontaneous imbibition in fractured low-permeability sands," SPE Reservoir Evaluation and Engineering, vol. 17, no. 1, pp. 74-81, 2014.

[39] R. F. Sigal, "Pore-Size distributions for organic-Shale- Reservoir rocks from nuclear-magnetic- resonance spectra combined with adsorption measurements," SPE Journal, vol. 20, no. 4, pp. 824-830, 2015.

[40] M. Meng, H. Ge, W. Ji, and X. Wang, "Research on the autoremoval mechanism of shale aqueous phase trapping using low field nuclear magnetic resonance technique," Journal of Petroleum Science and Engineering, vol. 137, pp. 63-73, 2016. 
[41] G. R. Coates, L. Xiao, and M. G. Prammer, NMR Logging: Principles and Applications, Gulf Professional Publishing, 1999.

[42] M. Appel, "Nuclear magnetic resonance and formation porosity," Petrophysics, vol. 45, no. 3, pp. 296-307, 2004.

[43] B. Roychaudhuri, T. T. Tsotsis, and K. Jessen, "An experimental investigation of spontaneous imbibition in gas shales," Journal of Petroleum Science and Engineering, vol. 111, pp. 87-97, 2013.

[44] J. M. Schembre, S. Akin, L. M. Castanier, and A. R. Kovscek, "Spontaneous water imbibition into diatomite," in Proceedings of the 1998 68th Annual Western Regional Meeting, May 1998.

[45] A. Javaheri, H. Dehghanpour, and J. M. Wood, “Tight rock wettability and its relationship to other petrophysical properties: a Montney case study," Journal of Earth Science, vol. 28, no. 2, pp. 381-390, 2017.

[46] M. Akbarabadi, "Nanotomography of Spontaneous Imbibition in Shale," in Proceedings of the Unconventional Resources Technology Conference (URTEC), 2014.

[47] M. Meng, H. Ge, W. Ji, X. Wang, and L. Chen, "Investigation on the variation of shale permeability with spontaneous imbibition time: Sandstones and volcanic rocks as comparative study," Journal of Natural Gas Science and Engineering, vol. 27, pp. 15461554, 2015.

[48] E. Fathi and I. Y. Akkutlu, "Multi-component gas transport and adsorption effects during $\mathrm{CO} 2$ injection and enhanced shale gas recovery," International Journal of Coal Geology, vol. 123, pp. 5261, 2014.

[49] A. Ghanizadeh, S. Bhowmik, O. Haeri-Ardakani, H. Sanei, and C. R. Clarkson, "A comparison of shale permeability coefficients derived using multiple non-steady-state measurement techniques: examples from the Duvernay Formation, Alberta (Canada)," Fuel, vol. 140, pp. 371-387, 2015.

[50] A. Sakhaee-Pour and S. Bryant, "Gas Permeability of Shale," SPE Reservoir Evaluation \& Engineering, vol. 15, no. 04, pp. 401-409, 2013.

[51] M. Zamirian, K. Aminian, S. Ameri, and E. Fathi, "New steadystate technique for measuring shale core plug permeability," in Proceedings of the SPE Canadian Unconventional Resources Conference 2014, pp. 598-608, October 2014.

[52] I. Yucel Akkutlu and E. Fathi, "Multiscale gas transport in shales with local kerogen heterogeneities," SPE Journal, vol. 17, no. 4, pp. 1002-1011, 2012.

[53] S. M. Kang, E. Fathi, R. J. Ambrose, I. Y. Akkutlu, and R. F. Sigal, "Carbon dioxide storage capacity of organic-rich shales," SPE Journal, vol. 16, no. 4, pp. 842-855, 2011.

[54] X. Fu, F. Agostini, F. Skoczylas, and L. Jeannin, "Experimental study of the stress dependence of the absolute and relative permeabilities of some tight gas sandstones," International Journal of Rock Mechanics and Mining Sciences, vol. 77, pp. 3643, 2015.

[55] Q. Lei, W. Xiong, J. Yuang, Y. Cui, and Y. Wu, "Analysis of stress sensitivity and its influence on oil production from tight reservoirs," in Proceedings of the Eastern Regional Meeting, 2007.

[56] R. A. Farquhar, B. G. D. Smart, A. C. Todd, D. E. Tompkins, and A. J. Tweedie, "Stress sensitivity of low petroleum sandstones from the rotliegendes sandstone," in Proceedings of the SPE Annual Technical Conference and Exhibition, pp. 851-861, Society of Petroleum Engineers, October 1993.

[57] H. Belyadi, E. Fathi, and F. Belyadi, "Managed pressure drawdown in Utica/Point Pleasant with case studies," in Proceedings of the 2016 SPE Eastern Regional Meeting, ERM 2016, September 2016.
[58] J.-J. Dong, J.-Y. Hsu, W.-J. Wu et al., "Stress-dependence of the permeability and porosity of sandstone and shale from TCDP Hole-A," International Journal of Rock Mechanics and Mining Sciences, vol. 47, no. 7, pp. 1141-1157, 2010.

[59] F. Civan, Reservoir Formation Damage, 2nd edition, 2007. 

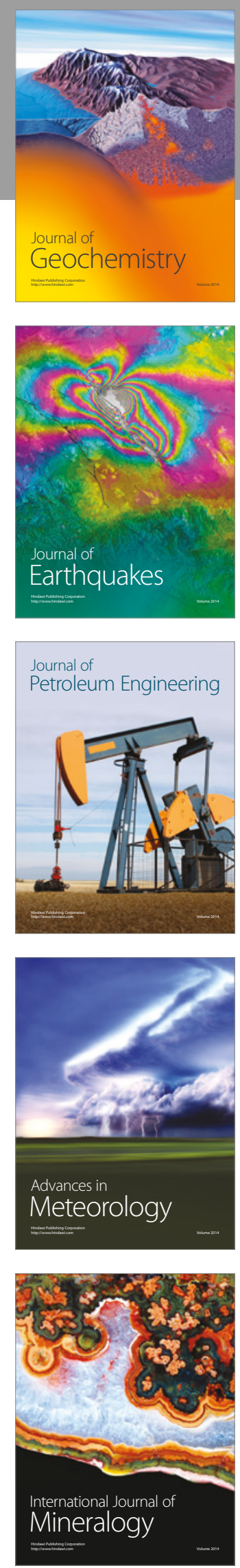
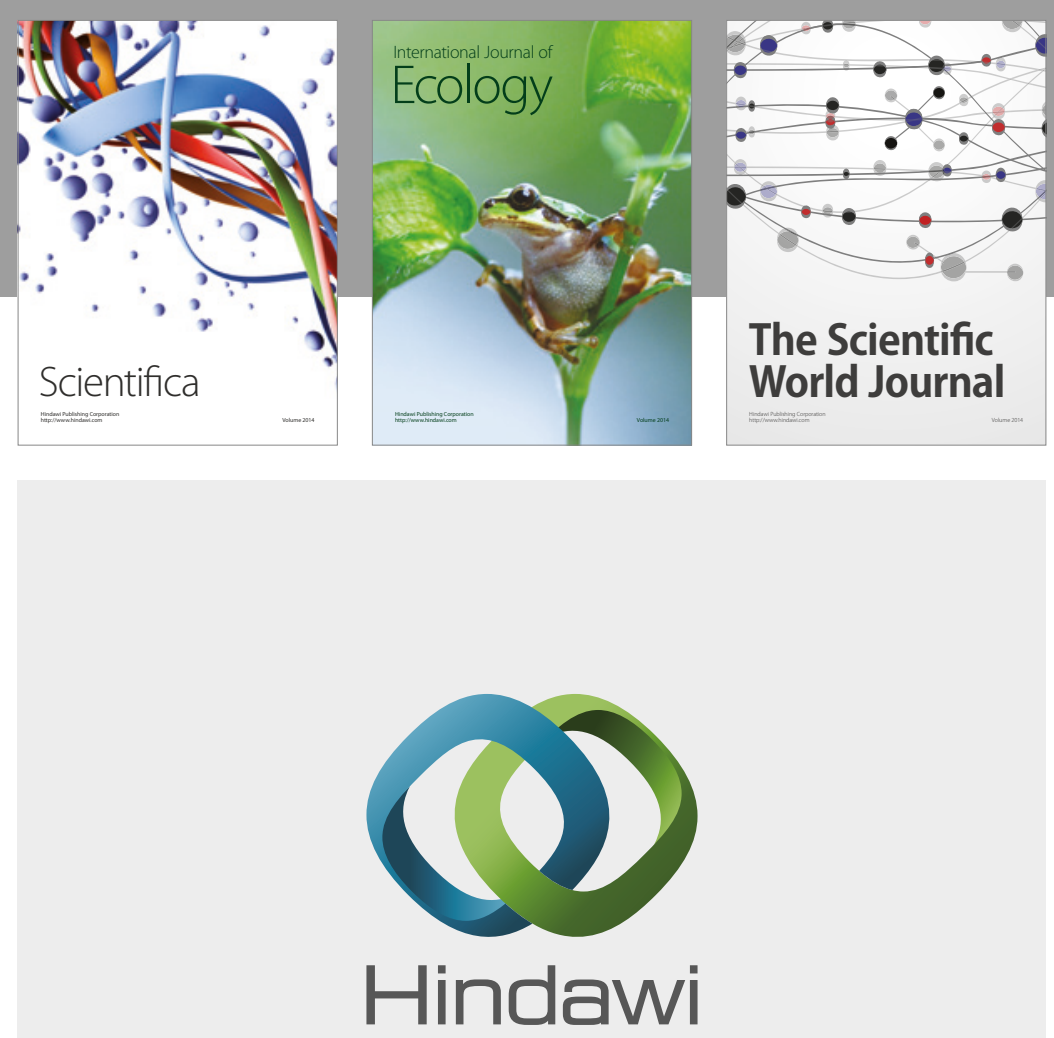

Submit your manuscripts at

https://www.hindawi.com
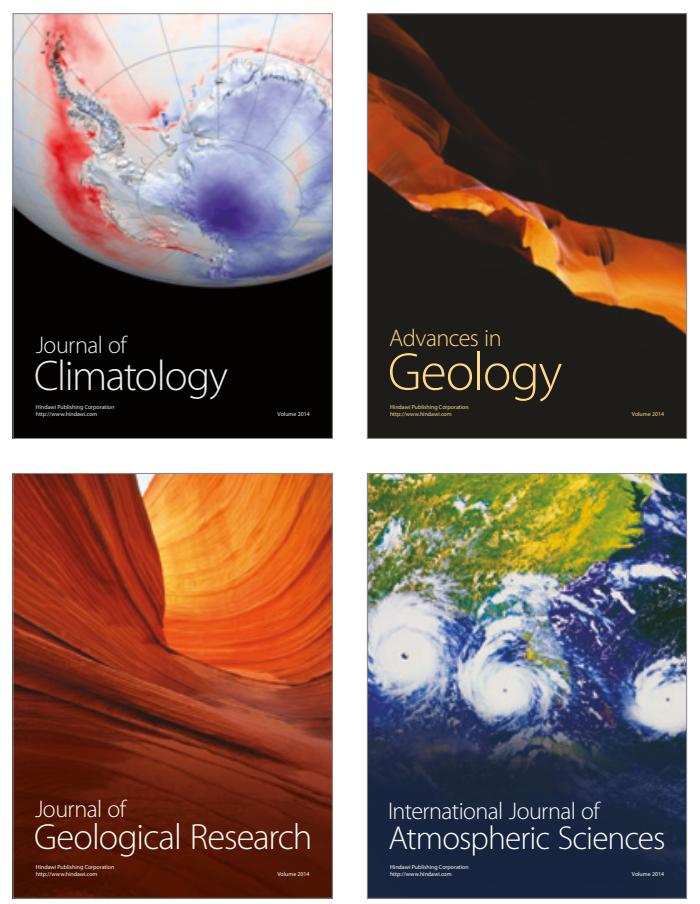

The Scientific

World Journal
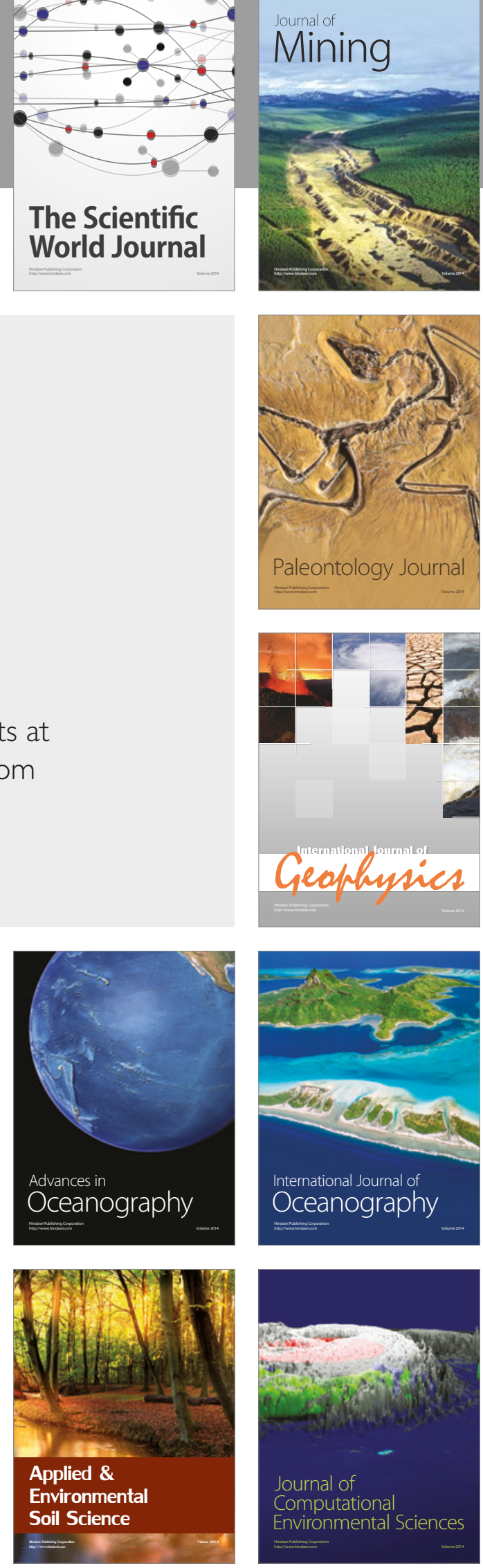